Tema: Aciaria Oxigênio

\title{
MODIFICAÇÃO DO PROCESSO DE MONTAGEM DO CANAL DE VAZAMENTO DO CONVERSOR LD*
}

\author{
Bruno Gomes Silva ${ }^{1}$ \\ Antonio Carlos Batista de Lima \\ Augusto Sergio Raimundo Filho ${ }^{3}$ \\ Sidney Gabriel de Paula ${ }^{4}$
}

\begin{abstract}
Resumo
Durante os reparos gerais nos conversores LD da CSN, as atividades de refratamento como demolição a quente, troca das ventaneiras, montagem do canal de vazamento e montagem do revestimento de trabalho e permanente, fazem parte do caminho critico do cronograma e são diretamente responsáveis pela dinâmica do evento. A montagem do canal de vazamento demandava uma série de atividades que exigiam maior tempo para execução e suporte para atividades em espaço confinado. Este trabalho apresenta sinergia entre fornecedores e diversas áreas envolvidas na montagem do canal de vazamento, onde a metodologia empregada resultou em redução no tempo de execução da atividade, disponibilidade da mão de obra e segurança operacional.
\end{abstract}

Palavras-chave: Canal de vazamento; Montagem; Reparo geral; Refratário; Conversor LD.

\section{MODIFICATION ASSEMBLY PROCESS OF TAPPING WELL BLOCK IN BOF LD}

\begin{abstract}
During the BOF's general repair in $\mathrm{CSN}$, the refractories activities like demolition of lining, tuyeres exchange, tapping well block assembly and work and safety lining assembly, belongs to critical path in schedule and are directly responsible in the event dynamics. The tapping well block assembly demanded many activities that spend a lot of time to done and also support to job location not suitable for. This work presents a synergy job between supplies and different departments involved in the tapping well block assembly where the methodology applied results in time reduction, man power availability and operational safety.
\end{abstract}

Keywords: Tapping well block; Assembly; General repair; Refractory; BOF.

1 Engenheiro Metalurgista, Engenheiro de Desenvolvimento Sênior, CSN/ GOS, Volta Redonda, Rio de Janeiro, Brasil.

2 Técnico em Mecânica, Técnico de Desenvolvimento Especialista, CSN/ GMA, Volta Redonda, Rio de Janeiro, Brasil.

3 Técnico em Mecânica, Técnico de Desenvolvimento, CSN/ GOS, Volta Redonda, Rio de Janeiro, Brasil.

4 Técnico em Mecânica, Técnico de Manutenção Mecânica, CSN/ GMA, Volta Redonda, Rio de Janeiro, Brasil.

* Contribuição técnica ao $45^{\circ}$ Seminário de Aciaria - Internacional, 25 a 28 de maio de 2014, Porto Alegre, RS, Brasil. 


\section{INTRODUÇÃo}

A siderurgia vem sofrendo fortes transformações como consequência da globalização. Independente da região, essas transformações visam buscar inovação para atender as necessidades dos clientes. Neste contexto, torna-se fundamental a melhoria de técnicas e materiais para produzir aços com menor custo e qualidade desejada.

$\mathrm{Na}$ siderurgia a palavra produtividade tem sido foco importante, onde as empresas do setor têm realizado grandes investimentos e despendido muita energia em projetos de melhorias para cada vez serem mais competitivas no mercado. No decorrer dos anos as práticas operacionais vêm evoluindo constantemente buscando alternativas e técnicas inovadoras com o objetivo de alcançar a maior eficiência dos equipamentos, maior confiabilidade e o nível de qualidade desejado.

Nas aciarias, o conversor LD é o equipamento responsável por transformar o ferro gusa em aço por meio de um processo de refino utilizando oxigênio. $O$ aço produzido pelos conversores é conduzido para um refino secundário e dependendo das características do produto pode ser tratado em diferentes estações, até estar nas condições desejáveis para ser lingotado nas máquinas de lingotamento contínuo, onde o produto que estava na fase liquida solidifica em forma de placas, tarugos ou blocos.

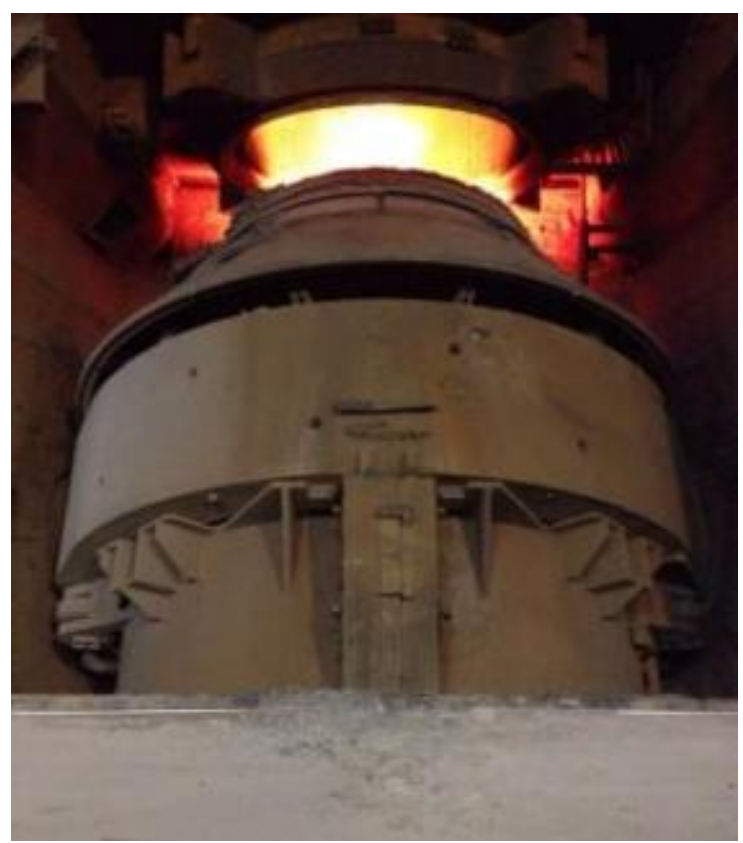

Figura 1. Conversor LD CSN.

A CSN possui três conversores LD e a disponibilidade para a operação é determinante para o escoamento da produção. O conversor é revestido de material refratário à base de Magnesia-Carbono e sua campanha dura em média 4500 corridas. Ao término de cada campanha o conversor é submetido a um reparo geral e atividades de manutenção refratária, mecânica, automação e civil são realizadas. O reparo geral dos conversores da CSN dura em torno de 10 a 15 dias, dependendo do numero de atividades a ser realizadas. A duração do evento varia de empresa para empresa, em função do tamanho do equipamento, efetivo e procedimentos adotados.

* Contribuição técnica ao $45^{\circ}$ Seminário de Aciaria - Internacional, 25 a 28 de maio de 2014, 
Nos reparos realizados na CSN, cerca de 450 colaboradores são deslocados para execução do cronograma de atividades, vindos de seis diferentes gerências e cerca de oito empresas terceirizadas.

O cronograma de atividades, de uma maneira simplificada, pode ser ilustrado na Figura 2.

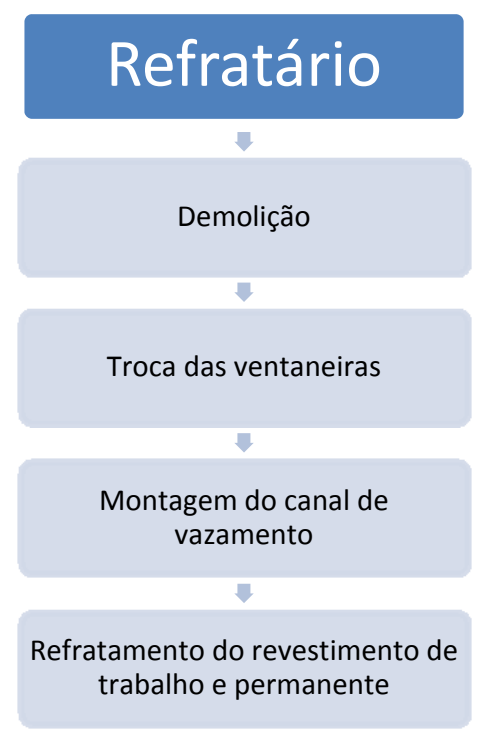

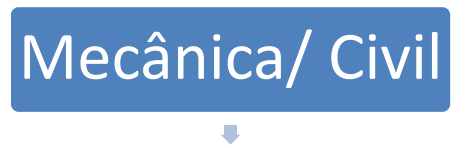

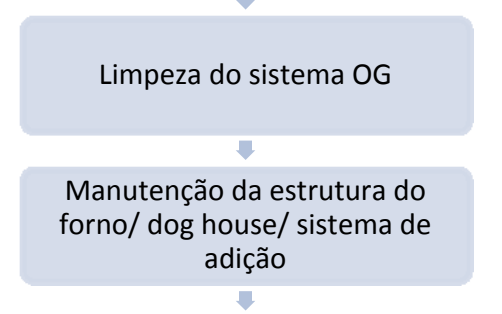

Manutenção Sub lança

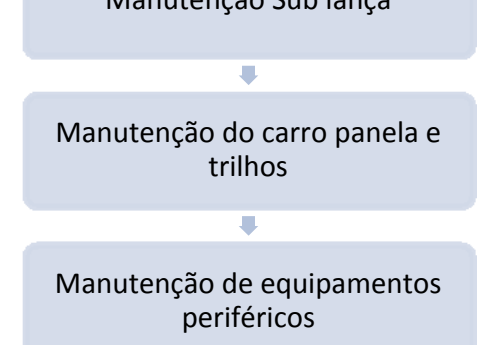

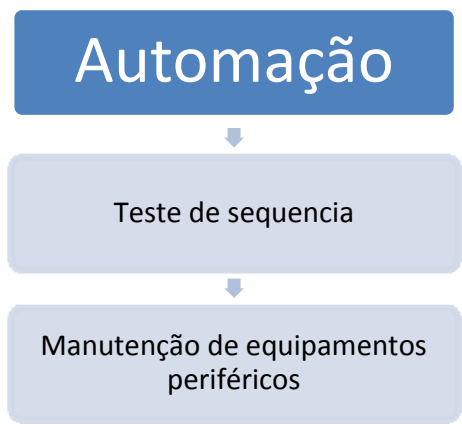
periféricos

Figura 2. Resumo Atividades Macro do Reparo Geral.

Durante os reparos gerais nos conversores LD da CSN, as atividades de manutenção refratária como demolição a quente, troca das ventaneiras, montagem do canal de vazamento e montagem do revestimento de trabalho e permanente, fazem parte do caminho crítico do cronograma e são diretamente responsáveis pela dinâmica do evento.

$\mathrm{Na}$ demolição a quente todo o refratário remanescente é retirado com o auxilio de uma máquina de ponteira e dependendo das condições do revestimento de segurança (permanente), pode ser reaproveitado para uma próxima campanha. Esta atividade dura em torno de 6 horas. A Figura 3 ilustra a atividade sendo executada pela máquina de ponteira.

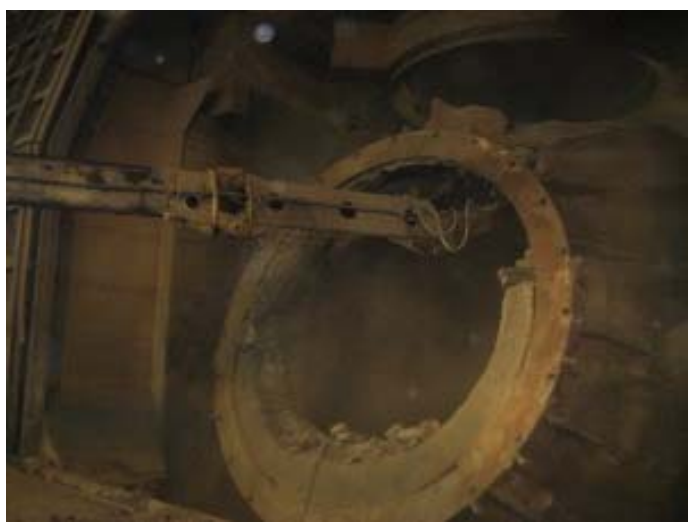

Figura 3. Demolição a quente do refratário.

* Contribuição técnica ao $45^{\circ}$ Seminário de Aciaria - Internacional, 25 a 28 de maio de 2014, 


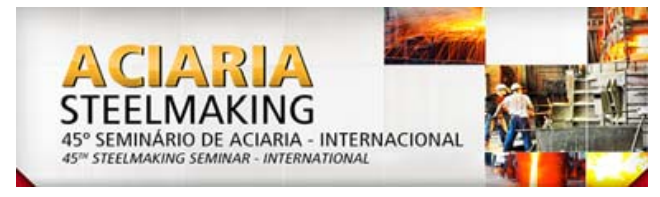

Após a retirada do revestimento de trabalho, o conversor é movimentado para que o fundo fique alinhado com a plataforma e as ventaneiras possam ser retiradas, conforme pode ser observado na Figura 4. A retirada das ventaneiras é realizada com a mesma máquina da demolição, porém com auxilio de olhais e manilhas, um cabo de aço é instalado na traseira da máquina e a mesma traciona puxando a peça para fora do conversor. Esta atividade dura em torno de 5 horas.

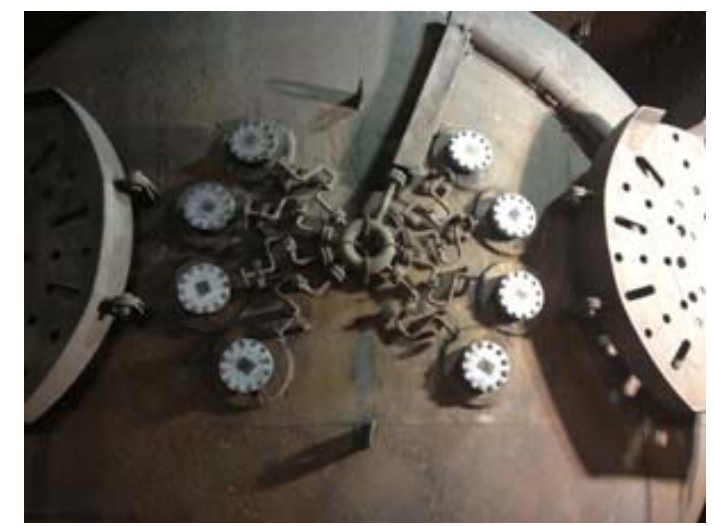

Figura 4. Fundo do conversor (vista externa) região das ventaneiras.

Seguindo o cronograma das atividades de refratamento a próxima etapa é a montagem do canal de vazamento. O canal de vazamento é a peça responsável por conduzir o aço produzido no conversor até a panela de aço, na Figura 5 retrata o momento que o conversor inicia o vazamento dentro da panela de aço.

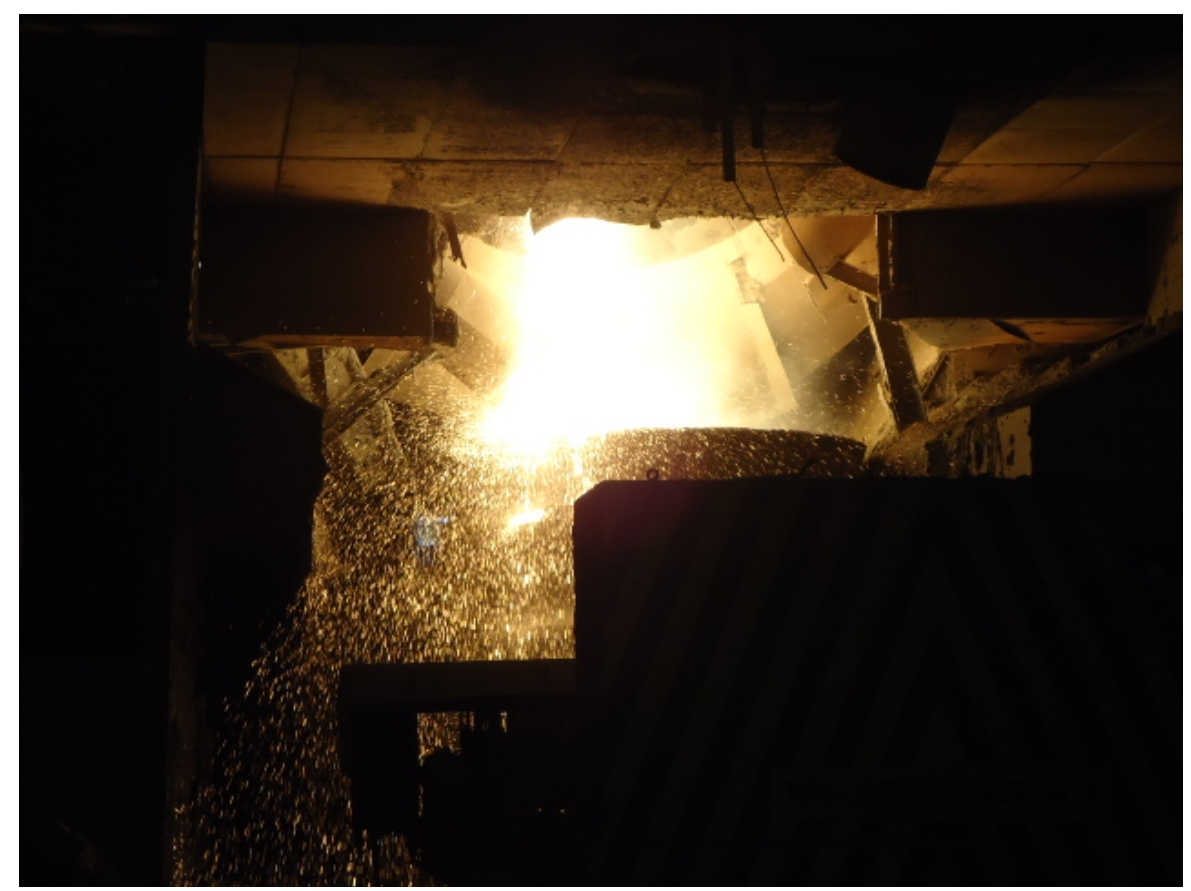

Figura 5. Vazamento do aço do Conversor LD para a Panela.

A Figura 6 ilustra o layout refratário que compõe a região do canal de vazamento do conversor LD da CSN.

* Contribuição técnica ao 450 Seminário de Aciaria - Internacional, 25 a 28 de maio de 2014, 

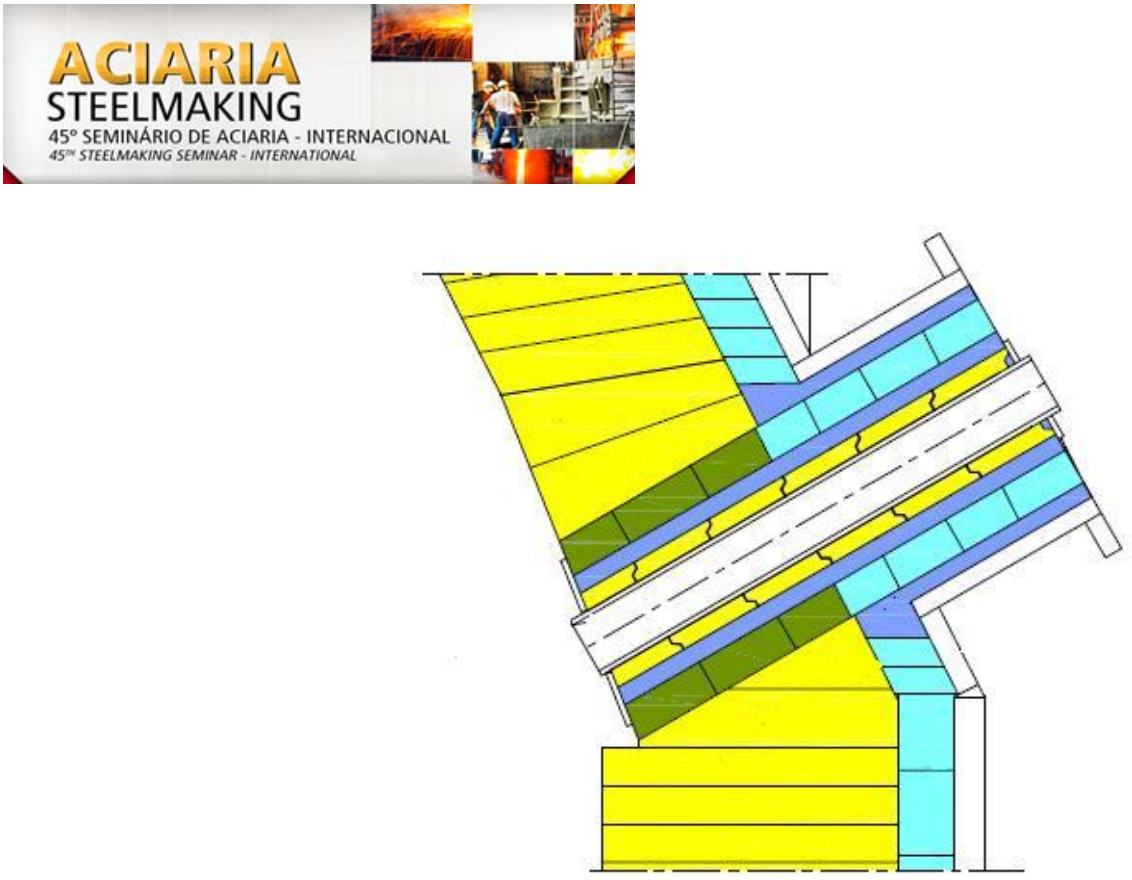

Figura 6. Vista projeto refratário do canal de vazamento.

A instalação do canal demanda uma série de recursos que exigem maior tempo para execução e suporte para atividades em espaço confinado. Na CSN a montagem do canal de vazamento já foi executada de várias maneiras.

Montagem por dentro (conversor a $0^{\circ}$ ): Seguindo a sequencia de refratamento do revestimento de trabalho o canal vinha totalmente desmontado e sua montagem era feita peça por peça, esse método era utilizado no passado e caiu em desuso, pois se gastava muito tempo para montagem da peça.

Montagem por dentro (conversor a $90^{\circ}$ ): Após a troca das ventaneiras, monta-se o acesso no interior do forno com andaimes, em seguida é instalada uma monovia onde o canal, já montado de fábrica, é conduzido até o interior do forno com um sistema de içamento, conforme pode ser visto na Figura 7. Durante a instalação da peça no orifício da carcaça a mesma é centralizada e concreto refratário é socado preenchendo o espaço vazio ao redor. Todas as atividades somadas duram 29 horas. Para essa atividade não é possível o reaproveitamento do revestimento de segurança (permanente) da região cilíndrica do forno, pois durante a instalação do canal pode haver risco de queda dos tijolos nas pessoas envolvidas na atividade.

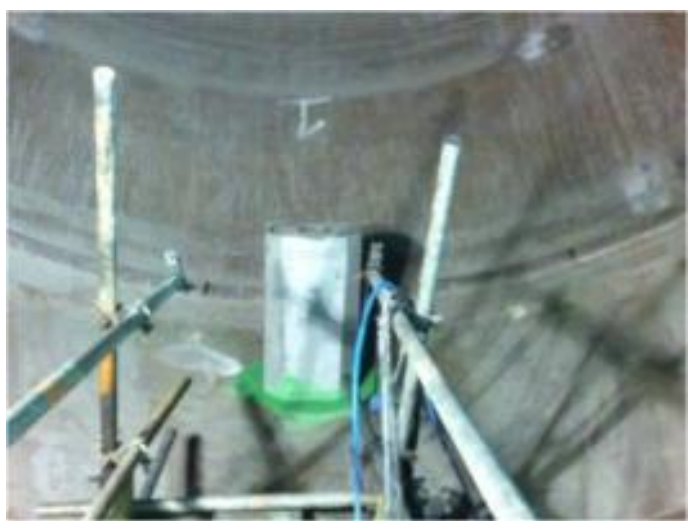

Figura 7. Canal instalado com o conversor a $90^{\circ}$.

Por fim, a última etapa das atividades de refratamento é a instalação do revestimento de trabalho do conversor. O conversor é posicionado a $0^{\circ}$ (posição de sopro) e um elevador é instalado em seu interior, proporcionando o abastecimento de pessoas e material.

* Contribuição técnica ao 45 Seminário de Aciaria - Internacional, 25 a 28 de maio de 2014, 

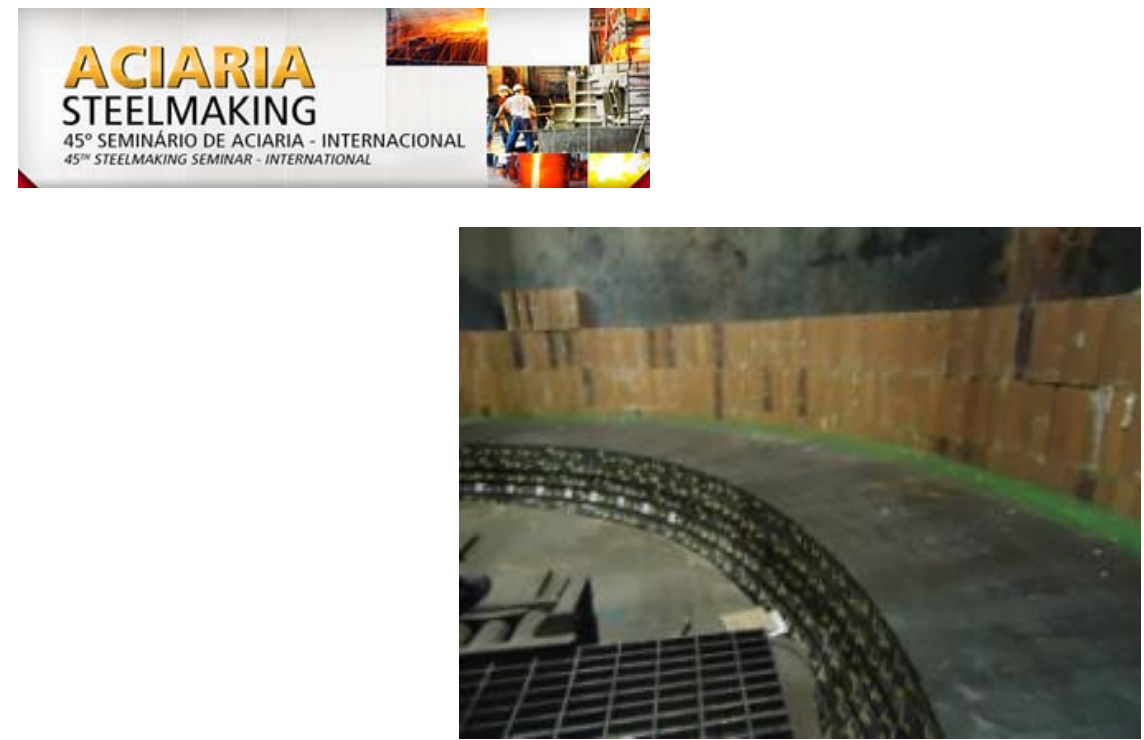

Figura 8. Instalação do revestimento de trabalho e permanente.

O conversor da CSN possui em torno de 77 fiadas de tijolos de trabalho e permanente, seu refratamento total dura 74 horas efetivas.

Analisando a atividade de instalação do canal de vazamento, onde o tempo despendido e os recursos necessários para execução da atividade com certos riscos de acidente, motiva para o desenvolvimento de um trabalho de melhoria. Este trabalho apresenta a modificação do método de montagem do canal de vazamento, onde o objetivo principal foi a redução no tempo de montagem e eliminação das atividades em condições de riscos para os colaboradores envolvidos.

\section{MATERIAIS E MÉTODOS}

Para realização do trabalho adotou-se a seguinte metodologia, com foco na observação da condição atual de montagem do canal de vazamento durante os reparos gerais dos conversores na CSN.

- Análise do procedimento de montagem do canal de vazamento;

o Pesquisa em outras empresas - "benchmarking";

o Verificação de recursos para alteração no método de montagem;

- Análise de geometria da peça (projeto);

- Pesquisa com os fornecedores de refratário sobre modificação da peça.

O trabalho teve seu inicio de maneira experimental no reparo geral do conversor $A$, campanha de número 125 , com o fornecedor do material refratário do revestimento de trabalho.

\section{RESULTADOS}

Durante a execução do "benchmarking", foi feito uma pesquisa de quais os procedimentos adotados por outras empresas e chegou-se a conclusão de que o método mais rápido e seguro era montagem inserindo a peça por fora da carcaça, com o conversor a $120^{\circ}$ (posição de retirada de escória), conforme pode ser observado na Figura 9. Com auxilio de um guindaste para içamento e centralização da peça

\footnotetext{
* Contribuição técnica ao $45^{\circ}$ Seminário de Aciaria - Internacional, 25 a 28 de maio de 2014,
} 

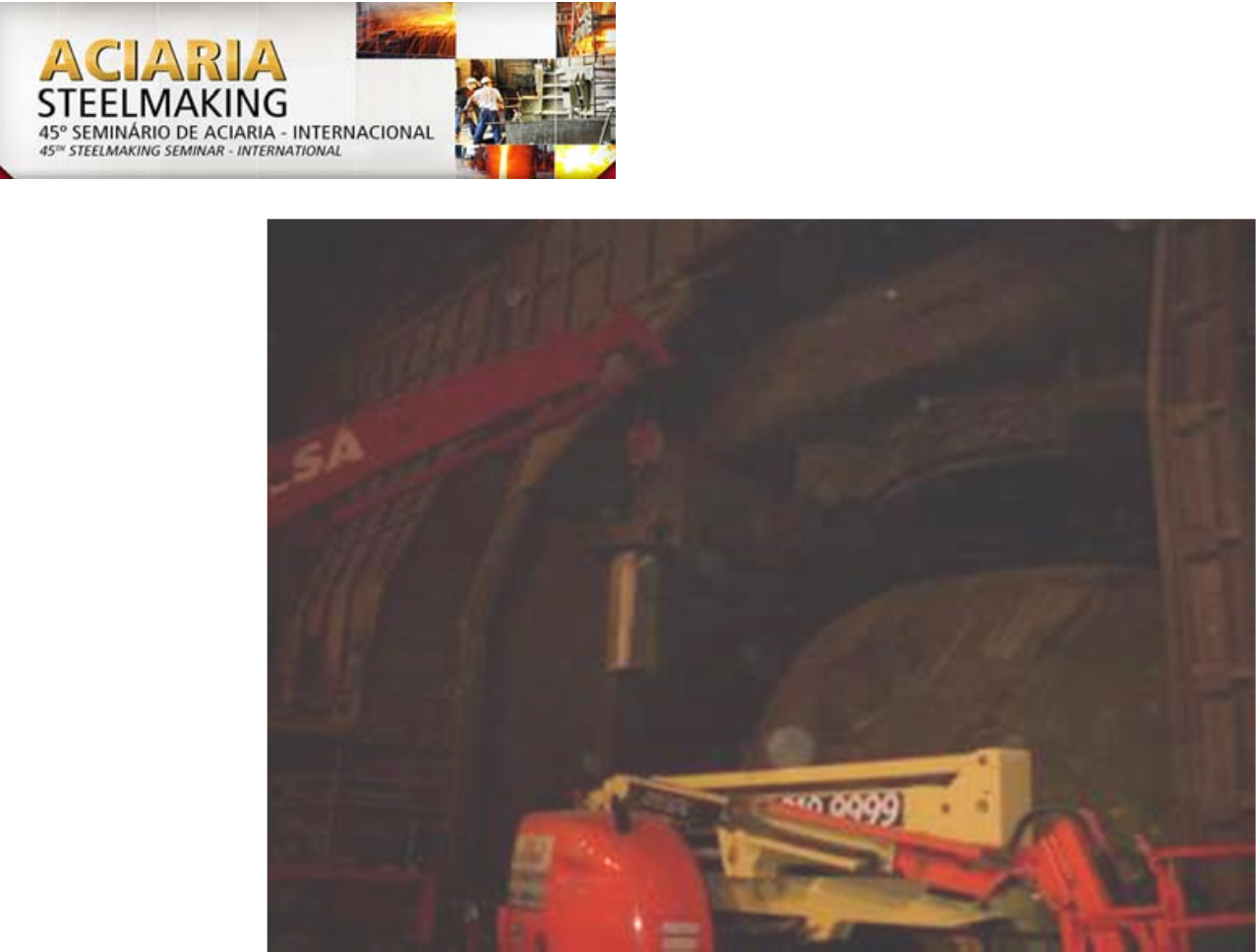

Figura 9. Instalação do canal de vazamento por fora (conversor a $120^{\circ}$ ).

Após a instalação da peça, os parafusos do flange são torqueados (Figura 10), fixando-a de modo que possibilite a movimentação do forno sem que haja deslocamento ou descentralização da mesma.

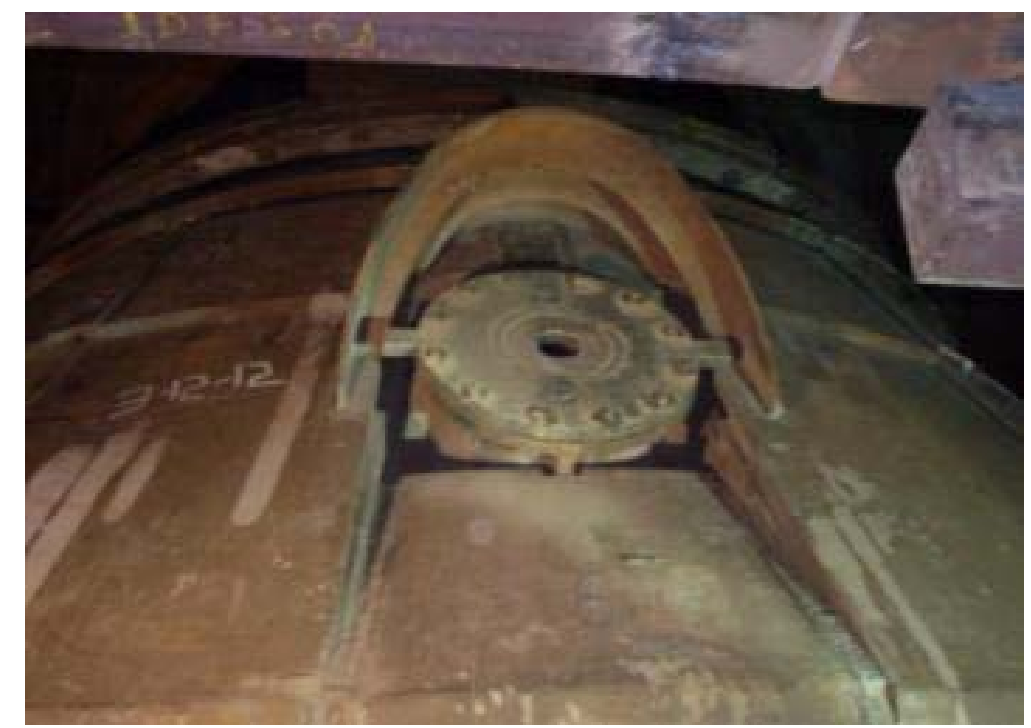

Figura 10. Vista externa do canal de vazamento com instalação finalizada.

Para que essa modificação no método de montagem pudesse ser executada, a peça teve que ser sofrer uma modificação no seu formato, possibilitando instalá-la por fora da carcaça onde o diâmetro do orifício da carcaça é $660 \mathrm{~mm}$ e a peça original, além de ter o formato de tronco de pirâmide, media $666 \mathrm{~mm}$, conforme pode ser observado nas Figuras 11 e 12.

* Contribuição técnica ao $45^{\circ}$ Seminário de Aciaria - Internacional, 25 a 28 de maio de 2014, Porto Alegre, RS, Brasil. 

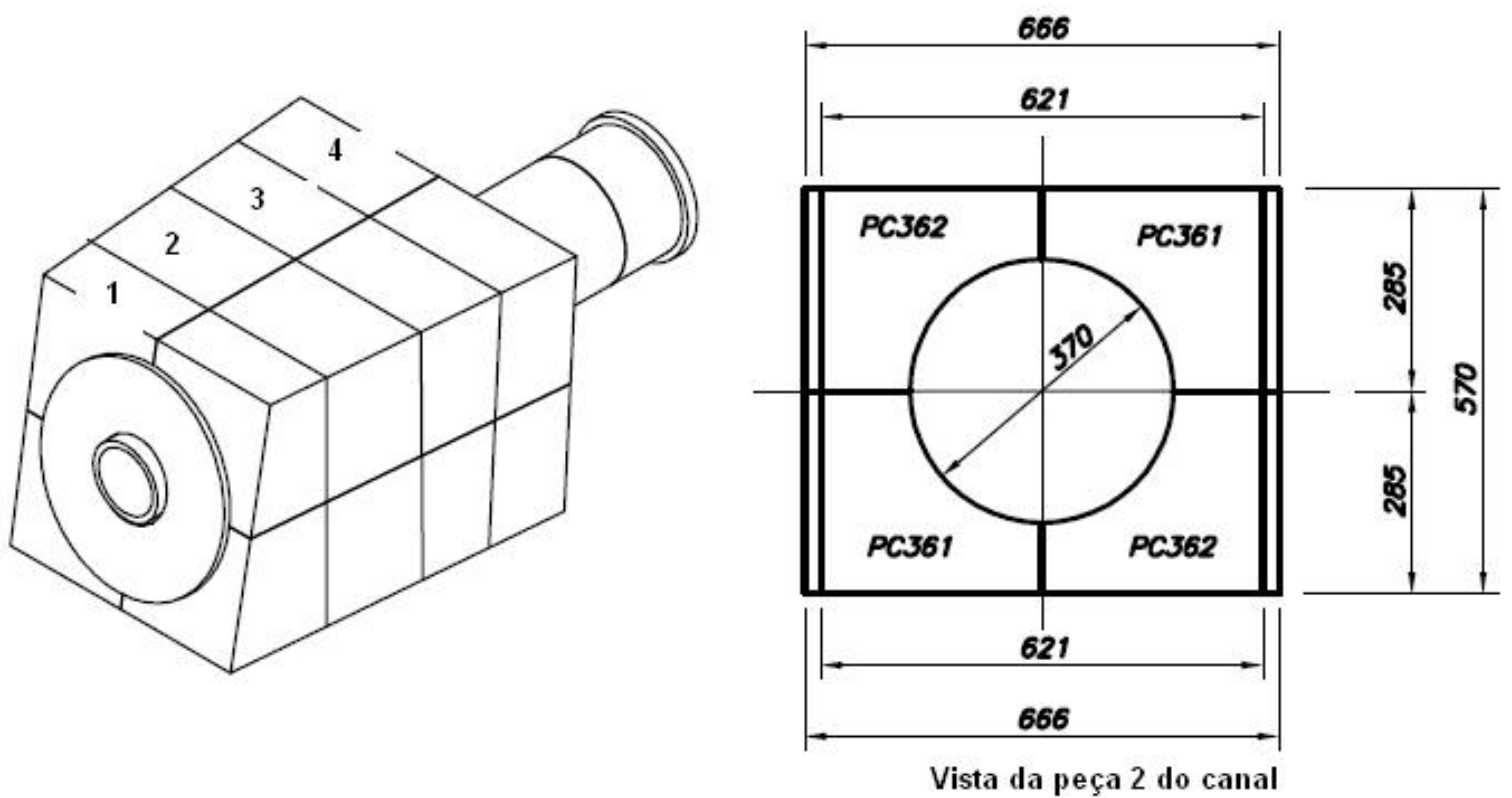

Figura 11. Canal de Vazamento (peça original).

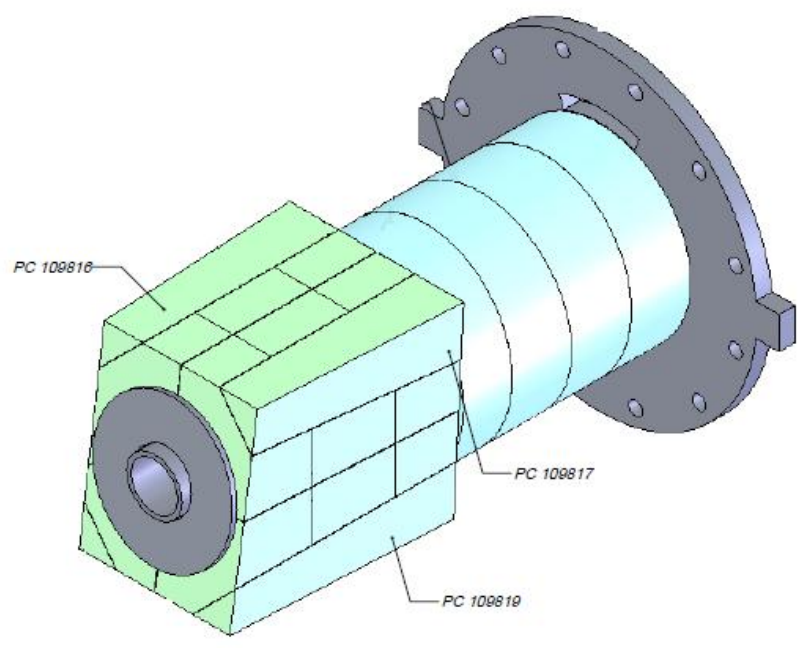

Figura 12. Canal de vazamento (peça modificada).

A modificação realizada no canal foi basicamente o corte das arestas da peça, proporcionando a passagem pelo orifício de $660 \mathrm{~mm}$. A Figura 13 mostra como ficou a peça modificada com as arestas separadas.
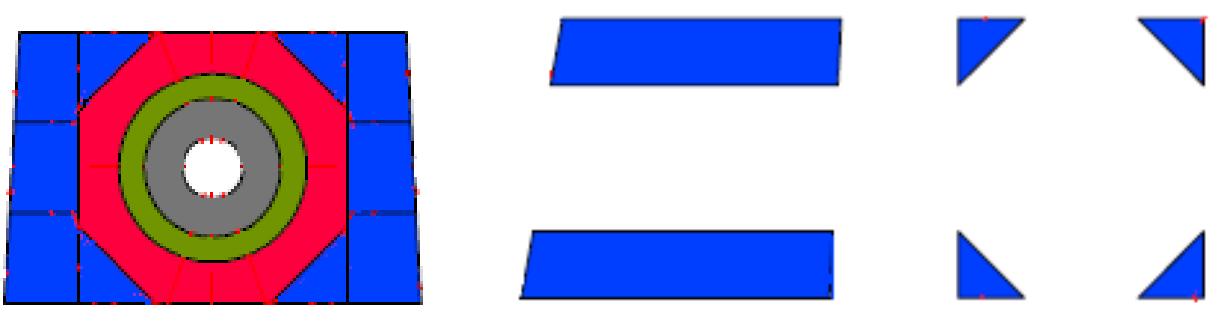

Figura 13. Vista frontal do canal de vazamento e detalhamento das peças cortadas.

* Contribuição técnica ao 450 Seminário de Aciaria - Internacional, 25 a 28 de maio de 2014, Porto Alegre, RS, Brasil. 


\section{DISCUSSÃO}

Com a modificação do método de montagem e a geometria da peça alterada, foi possível obter outros ganhos, que de certa maneira enaltece o resultado alcançado pela simplicidade das ações que foram tomadas.

Eliminando a montagem do canal com o conversor a $90^{\circ}$, foi eliminado também as atividades de montagem de acesso no interior do forno e monovia para movimentação do canal, resultando em um ganho de 25 horas na atividade macro no cronograma do reparo geral. A mão de obra envolvida nas atividades é disponibilizada para atender outras frentes de serviço. O novo método dura apenas 4 horas para instalação do canal e fixação do flange na carcaça do forno.

Com o novo método de montagem, o acesso de pessoas no interior do forno não é necessário, proporcionando não só o ganho em condição segura de trabalho aos operadores envolvidos na atividade, quanto o reaproveitamento do refratário permanente na região do cilindro e cone superior do conversor.

Em uma visão anual, são realizados cinco reparos gerais e a cada reparo é gerado 122 toneladas de refratário permanente, totalizando 610 toneladas/ano de resíduo refratário. Para o Meio Ambiente, proporcionando o reaproveitamento do revestimento permanente, pelo menos três revestimentos são recuperados e a geração de 366 toneladas de resíduos provenientes a cada demolição do forno é reduzida.

Em relação aos ganhos econômicos, com os dados de produção de dois e três conversores, os ganhos potenciais em função da redução no tempo de montagem do canal foram na ordem de $\mathrm{R} \$ 3$ Milhões. Teoricamente, reduzindo o tempo de montagem do canal, o caminho crítico do cronograma reduz proporcionalmente, porém existem atividades paralelas ao caminho critico que dependendo da dinâmica do evento, passam a integrar o caminho crítico.

\section{CONCLUSÃO}

A modificação no processo de montagem do canal de vazamento foi aprovada e implantada.

O resultado apresentado foi obtido através da sinergia entre fornecedores e diversas áreas envolvidas na atividade, a metodologia empregada resultou na redução no tempo de execução da atividade, disponibilidade da mão de obra, redução na geração de resíduo refratário do revestimento permanente e segurança operacional. Dando continuidade no trabalho de melhoria contínua, a próxima etapa será o flange vir soldado de fábrica e o concreto refratário socado no espaçamento entre a peça e a carcaça do forno será aplicado por fora do conversor.

\section{Agradecimentos}

A toda equipe envolvida no trabalho. A dedicação e empenho foram de suma importância para o sucesso e o grande resultado obtido.

Aos fornecedores dos materiais refratários $\mathrm{RHI}$ e Magnesita em especial Manoel Felipe, assistente técnico da empresa $\mathrm{RHI}$, que foi o grande incentivador e orientador na execução desse projeto.

* Contribuição técnica ao $45^{\circ}$ Seminário de Aciaria - Internacional, 25 a 28 de maio de 2014, 